\title{
Acute polyneuropathy due to lightning injury
}

\author{
C H Hawkes, J W Thorpe
}

\begin{abstract}
The case of a 19 year old man struck by lightning is described. He sustained quadriplegia for several months and fully recovered. It is suggested that his weakness was due to extensive peripheral nerve damage. In addition, he displayed many well recognised medical complications of lightning injury including acute renal failure, rhabdomyolysis, respiratory distress syndrome, autonomic dysfunction, perforated ear drum, uveitis and cataract. The literature relating to the neurology of lightning strike is briefly reviewed.
\end{abstract}

In Britain about 12 people each year are struck by lightning, three or four of whom will be killed. Whilst weakness lasting approximately 24 hours is well recognised, more permanent sequelae are infrequent and poorly understood from the pathological and clinical aspects.

\section{Case report}

A 19 year old left handed male docker was admitted on 4 May 1988 after being struck by lightning while astride a stationary motorcycle. He rolled into a nearby ditch part-filled with water and was found apnoeic and cyanosed. His helmet was virtually destroyed by the lightning. On hospital admission he was deeply unconscious (Glasgow Coma Scale 3), tachypnoeic, cyanosed, but peripheral pulses were palpable. Pupils were small and fixed, BP $240 / 140$. He had sustained burns to $20 \%$ of his total body surface. These consisted of a flash burn of the face, anterior neck and upper chest which were superficial. There was a burn to the right arm which was patchily deep and a clear electrical injury to the left II-IV digits on their volar surfaces. The middle and ring fingers on the left were severely damaged with open flexor sheaths and poor circulation. There were well demarcated burns on both calves which were probably electrical, but might have been due to contact with a hot engine or exhaust of the motor-cycle. A subtotal perforation of the right ear was noted. He was immediately intubated, ventilated and catheterised.

Investigations revealed hypercalcaemia with acute renal failure and hyperkalaemia. Urinalysis was positive for myoglobin. Bilateral shadowing on the chest $x$-ray suggested aspiration and a cardiograph showed large QRS complexes $(7 \mathrm{mV})$ with $S-T$ elevation in the right chest leads compatible with severe electrolyte imbalance.

Treatment was started with insulin and dextrose infusion, ranitidine, calcium gluconate, dexamethasone and cephradine. His burns were dressed in standard fashion and his condition improved over the following 24 hours, with return of pupillary reactions.

Over the following two days he developed an acute respiratory distress syndrome followed by autonomic dysfunction, that is, hypertension, tachycardia, hyperpyrexia and severe paralytic ileus.

When examined on 20 May 1988, he was breathing spontaneously, alert, reasonably well orientated and responding to verbal commands. Ocular movement, pupillary light reflexes and fundoscopy were all normal. Phonation was initially very quiet and respiration diaphragmatic. In the limbs there was a flaccid quadriparesis with no voluntary lower limb movement. In the upper limb he could shrug only the left shoulder and perform slight finger flexion with the left hand. The knee jerks were just obtainable but all other tendon reflexes were lost. Plantar responses were both flexor. Sensation was probably impaired below groin level and he continued to require a catheter. The provisional neurological diagnosis was that of acute lower cervical myelopathy with spinal shock secondary to electrical injury. Following cessation of artificial respiration he developed three further complications: left ileo-femoral thrombosis; infection of the right ear in association with the perforated drum; right sided uveitis.

Split skin grafts were used to repair burns to the right elbow and calves. A pedicle graft was raised from the left groin to cover a full thickness burn on the left hand at which time it was noted that all the left digital arteries were thrombosed. Many digital nerves looked unhealthy but were left intact.

With intensive physiotherapy he recovered the ability to stand and the arms had regained further power one month after admission. Detailed neurological examination was limited because of surgical dressings but it was clear (on 20 July 1988) that there was now marked wasting in the right forearm and hand with again depressed tendon reflexes. Joint position sense was impaired as far as the right wrist. The lower limb tendon reflexes were normal. Eventually he was discharged home, walking with sticks, 12 weeks after admission.

Over the following year he generally 
improved. Further plastic surgery was required for contracture of the left fingers. Myringoplasty was performed on the ruptured tympanic membrane. Six months after the injury he developed a dense right cataract which was removed.

In July 1989 (14 months after the accident) he was back to normal activities. Whilst out sailboarding he was briefly stunned by the boom and admitted because of headache and vomiting. A CT revealed no intracranial haemorrhage but there was quite marked dilatation of the entire ventricular system. Presumably this was due to cerebral atrophy from cerebral oedema and/or hypoxia at the time of lightning strike. The alternative more remote possibility of communicating hydrocephalus could not be addressed as he declined lumbar puncture. At this time arm function was normal except for depressed tendon reflexes. There was minor weakness of both hip flexors and both plantar responses were now extensor.

\section{Neurophysiological tests}

Nerve conduction studies were undertaken on three separate occasions (see table). Comprehensive examination was not always possible because of surgical dressings or the presence of burnt skin close to recording or stimulation sites. The first study showed involvement of the right median nerve with sparing of the ulnar nerve on that side (the left arm could not be tested). The more detailed examination in September 1988 (4 months after injury) showed that both median nerves were affected with increased terminal motor latency and absent sensory nerve action potentials (SNAPs). The lower limb values (both common peroneal and sural) were within normal limits. At the final examination the right median motor values had returned to near normal apart from a slight increase of terminal latency and small SNAPs were obtainable for the first time.

An electromyogram in October 1988 and September 1989 showed clear evidence of denervation in the intrinsic hand muscles and tibialis anterior. Striking pseudo-myotonic discharges were seen especially in the leg muscles. A cortical magnetic evoked potential study was attempted in October 1988 and September 1989 but on neither occasion could a response be obtained from the abductor digiti minimi. Somatosensory responses were attempted in
September 1989 with stimulation of either median nerve. The $\mathrm{N} 9$ responses were of low voltage $(1 \mu \mathrm{V})$ and the parietal potentials small, ill defined but probably not delayed $(17.6 \mathrm{mS} ; 18.5 \mathrm{mS}$ on right and left median nerve stimulation respectively; both $0.5 \mu \mathrm{V}$ ).

\section{Discussion}

Quadriplegia lasting more than a few days as a result of being struck by lightning is a very rare condition, and delayed recovery to such a complete degree as in our case is even less common. Our patient showed many well recognised general medical complications-renal failure, hypercalcaemia, rhabdomyolysis, shock lung, dysautonomia perforated ear drum, uveitis and cataract.

Neurologically he displayed a flaccid quadriplegia. Initially this could have related to spinal shock but the prolonged recovery over six months excludes this and one has to consider peripheral nerve spinal cord disorder. Despite near complete clinical recovery there was no evidence that the quadriplegia resulted from corticospinal tract damage as muscle tone and the tendon reflexes were never increased. Although the plantar responses ultimately became extensor this could have been due to cerebral atrophy described above. All the motor signs were lower motor neuron in type and the sensory nerve action potentials either small or absent, which would suggest direct damage to the peripheral nerves, but it is still possible that the anterior horn cells were damaged as well. It is probable that the lightning travelled between both hands and across the neck affecting the spinal cord en route without travelling up and down the spinal cord, hence the long tracts were spared. We do not think there was simply a combined median and ulnar lesion in the right hand as the wasting extended to shoulder level, nor was there evidence of median nerve compression from scar tissue at the wrist although both of these complications have been described. ${ }^{12}$ The clear evidence of digital artery thrombosis on the left side suggests that nerve ischaemia was an important contributory factor in our case. There was most likely a similar "stride" potential between the legs as the burns were maximal at the inner part of the ankles. This probably caused the leg weakness but for some reason the peripheral leg nerves were not badly

Table

\begin{tabular}{|c|c|c|c|c|c|}
\hline Nerve & Date & $\begin{array}{l}\text { Terminal motor } \\
\text { Latency }\end{array}$ & $\begin{array}{l}\text { F Response } \\
\text { Latency }\end{array}$ & $\begin{array}{l}\text { Conduction Velocity } \\
\text { Metres/second }\end{array}$ & $S N A P^{*}$ \\
\hline $\begin{array}{l}\text { R Median } \\
\text { R Ulnar }\end{array}$ & 14 July 1988 & $\begin{array}{l}\text { Absent } \\
3.6 \mathrm{mS} 1.5 \mathrm{mV}\end{array}$ & Absent & $\begin{array}{l}\text { Absent } \\
40 \mathrm{M} / \mathrm{s}\end{array}$ & $2.3 \mathrm{mS} 5 \mu \mathrm{v}$ \\
\hline R Median & 21 September & $4.6 \mathrm{mS} 1.0 \mathrm{mV}$ & $34.8200 \mu \mathrm{V}$ & $31 \cdot 1$ & Absent \\
\hline $\begin{array}{l}\text { L Median } \\
\text { R Ulnar } \\
\text { L Ulnar } \\
\text { R CP } \\
\text { L CP } \\
\text { R sural }\end{array}$ & & $\begin{array}{l}5.2 \mathrm{mS} 1.5 \mathrm{mV} \\
3.8 \mathrm{mS} 1.5 \mathrm{mV} \\
3.0 \mathrm{mS} 4.0 \mathrm{mV} \\
4.8 \mathrm{mS} 3.6 \mathrm{mV} \\
3.4 \mathrm{mS} 4.0 \mathrm{mV}\end{array}$ & $\begin{array}{l}29.7500 \mu \mathrm{V} \\
37.4300 \mu \mathrm{V} \\
33.0200 \mu \mathrm{V} \\
55.2200 \mu \mathrm{V} \\
55.5200 \mu \mathrm{V}\end{array}$ & $\begin{array}{l}41 \cdot 0 \\
50.8 \\
46.0 \\
40.6 \\
47.0 \\
42 \cdot 0\end{array}$ & $\begin{array}{l}\begin{array}{c}\text { Absent } \\
\text { Absent } \\
\text { Absent }\end{array} \\
4.3 \mathrm{mS} 8 \mu \mathrm{V}\end{array}$ \\
\hline $\begin{array}{l}\text { R Median } \\
\text { R Ulnar }\end{array}$ & 12 October 1989 & $\begin{array}{l}5.4 \mathrm{mS} 1 \mathrm{mV} \\
3.3 \mathrm{mS} 4 \mathrm{mV}\end{array}$ & $\begin{array}{l}\text { Absent } \\
31.4 \mathrm{mS}\end{array}$ & $\begin{array}{l}58 \cdot 0 \\
60 \cdot 5\end{array}$ & $\begin{array}{l}4.4 \mathrm{mS} 3 \mu \mathrm{V} \\
2.7 \mathrm{mS} 4 \mu \mathrm{V}\end{array}$ \\
\hline
\end{tabular}

$\star=$ Sensory nerve action potential. 
affected. The bladder paralysis could have been due to autonomic dysfunction of which there was ample evidence early on. Overall we suspect damage to peripheral nerves including the anterior horn cells.

According to earlier estimates only $3 \%$ of patients ${ }^{3}$ exposed to electrical shock have neurological complication but this must be an underestimate as others have found limb weakness in $60-70 \% .^{45}$ Immediate effects of lightning include loss of consciousness-due to syncope or concussion-and usually amnesia for the event. Thereafter para- or quadriplegia may be detected generally when consciousness is regained. In most instances, weakness resolves within 24 hours ("keraunoparalysis"). Because of associated peripheral vascular changes (that is, cyanosis, coldness of extremities) it has been suggested that the paralysis is due to intense vasoconstriction brought about by massive autonomic stimulation. ${ }^{6}$ Apart from these organically based phenomena, hysterical weakness is also seen.

Several neurological sequelae are recognised: 1) Cerebral oedema. This is frequent, sometimes developing rapidly and fatally. ${ }^{7}$ Direct cortical damage, epidural and subdural haematomata are all associated. ${ }^{8}$ Rarely a cerebellar syndrome is seen ${ }^{9}$ and less frequently still, epilepsy choreoathetosis and perhaps Parkinsonism. The authenticity of many of the latter observations is open to question as the contribution of trauma from a direct blow to the head is not always known. Furthermore some cerebral hypoxia is inevitable in severe cases and the role of this is not always assessed. 2) Limb Weakness. A small (so far unquantified) proportion of subjects suffer more permanent weakness of the limbs in various combinations secondary to myelopathy. ${ }^{46}$ Delayed paraplegia after lightning strike is well recognised. ${ }^{6}$ Later, a syndrome resembling amyotrophic lateral sclerosis is said to develop ${ }^{11}$ but is probably a chance association. 3) Peripheral nerve damage. Such nerves may be injured directly by lightning or compressed from burn scars or fractures. ${ }^{12}$ Some have suggested that electrical current might cause conduction block in a peripheral nerve. ${ }^{613}$ Polyradiculoneuropathy has been recorded ${ }^{14}$ and appears to develop when there are multiple points of entry, as in our case.

Little is known of the neuropathology of lightning injury; with respect to peripheral nerves and spinal cord lesions it has proved difficult to separate direct electrical effects upon nerve from secondary damage due to vascular pathology. In the brain, effects of hypoxia inevitably has complicated interpretation. Critchley ${ }^{3}$ described multifocal petechial haemorrhages throughout the cerebral cortex, medulla and spinal grey matter with widespread chromatolysis. In peripheral nerve, fragmentation and tortuosity of axons was seen with degeneration of Schwann cells sheaths, some of which showed localised ballooning.

Myelopathy has been associated with compression by haematomata, cord oedema and/or multiple petechial haemorrhage. ${ }^{6}$ In one case of progressive myelopathy, ${ }^{15}$ there was demyelination of the pyramidal tracts and posterior columns with extensive associated gliotic reaction. Patients with delayed myelopathy have been carefully evaluated ${ }^{101617}$ and the consensus view is that a primary demyelinating myelopathy occurs without evidence of axonal degeneration, vascular change or inflammation.

The clinical spectrum of neurological damage due to lightning injury is fairly well described in the literature. Our patient displayed polyneuropathy which is one of the rarer complications. Further documentation of neuropathological abnormalities is badly needed.

1 Wilkinson C, Wood $M$. High voltage electric injury. $\operatorname{Am} \mathcal{F}$ Surg 1978;136:693-6.

2 Esses SI, Peters WJ. Electrical burns: pathophysiology and complications. Can $\mathcal{F}$ Surg 1981;24:11-14.

3 Critchley M. Neurological effects of lighting and of electricity. Lancet 1934;1:68-72.

4 Cooper MA. Lightning injuries: prognostic signs for death. Ann Emerg Med 1980;9:134-8.

5 Iranyi K, Iranyi J, Orovecz B, Somogyi E. Neuropsychiatrische Erscheinungen nach Blitzschlagunfallen. Psychiat Neurol Med Psychol (Lpz) 1964;6:310-5.

6 Panse F. Electrical trauma. Handbook Clin Neurol 1975;23:683-729.

7 Hanson GC, Mcllwraith GR. Lightning injury: two case histories and a review of management. $B M F$ 1973;4:271-4

8 Cwinn AA, Cantrill SV. Lightning injuries. fourn of Emerg Medicine 1985;2:379-88.

9 Suri ML, and Vijayan GP. Neurological sequelae of lightning. fourn Asso Physicians India 1978;26:209-12.

10 Davidson GS, Deck JH. Delayed myelopathy following lightning strike: a demyelinating process. Acta Neuropathol 1988;77:104-8.

11 Panse F. Electrical lesions of the nervous system. In: Vinken PJ, Bruyn GW, eds. Handbook of clinical neurology, Vol 7: Diseases of nerves, PII. Amsterdam: North-Holland, 1970:344-87.

12 Savitsky U, Gerson MJ. Peripheral nerve injury following electrical trauma: axillary and radial nerve involvement. Fournal of Nervous and Mental Disease 1942;96:635-40.

13 DiVicenti FC, Moncrief JA, Pruitt BA. Electrical injuries: a review of 65 cases. I Trauma 1969;9:497-507.

14 Critchley $M$. The effects of lightning with especial reference to the nervous system. Bristol Med Chir four 1932; Vol XIIX:285-300.

15 Gerhard L, Spancken E. Chronische Ruckenmarksschadigung nach Starkstromunfall. Acta Neuropathol (Berl) gung nach Star

16 Farell DF, Star A. Delayed neurological sequelae of electrical injuries. Neurology 1968;18:601-6.

17 Levine NS, Atkins A, McKeel DW, Peck SD, and Pruitt BA. Spinal cord injury following electrical accidents: case reports. f Trauma 1975;15:459-63. 